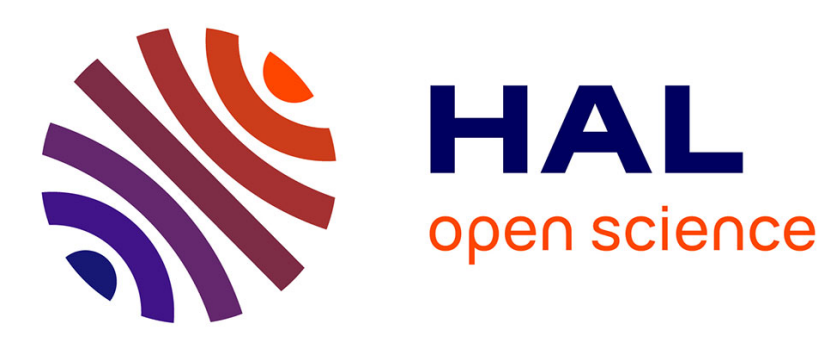

\title{
Considering Aesthetics and Usability Temporalities in a Model Based Development Process
}

\author{
Sophie Dupuy-Chessa, Yann Laurillau, Eric Céret
}

\section{To cite this version:}

Sophie Dupuy-Chessa, Yann Laurillau, Eric Céret. Considering Aesthetics and Usability Temporalities in a Model Based Development Process. Actes de la 28ième conférence francophone sur l'Interaction Homme-Machine, Oct 2016, Fribourg, Switzerland. pp.25-35, 10.1145/3004107.3004122 . hal-01383714

\section{HAL Id: hal-01383714 https://hal.science/hal-01383714}

Submitted on 19 Oct 2016

HAL is a multi-disciplinary open access archive for the deposit and dissemination of scientific research documents, whether they are published or not. The documents may come from teaching and research institutions in France or abroad, or from public or private research centers.
L'archive ouverte pluridisciplinaire HAL, est destinée au dépôt et à la diffusion de documents scientifiques de niveau recherche, publiés ou non, émanant des établissements d'enseignement et de recherche français ou étrangers, des laboratoires publics ou privés. 


\title{
Considering Aesthetics and Usability Temporalities in a Model Based Development Process
}

\author{
Sophie Dupuy-Chessa, Yann Laurillau, Eric Céret \\ Université Grenoble Alpes, LIG, CNRS \\ Bâtiment IMAG, Domaine Universitaire, F-38000 Grenoble, France \\ firstname.lastname@imag.fr
}

\section{RÉSUMÉ}

L'ingénierie dirigée par les modèles offre des solutions pour créer interfaces utilisateurs, en particulier dans le cas d'interfaces complexes, comme celles adaptables à leur contexte d'usage. Cependant, ces interfaces souffrent d'une faible qualité. Cet article aborde ce problème en intégrant des étapes d'étude de l'esthétique et de l'utilisabilité dans un processus de développement basé sur les modèles, qui s'appuie sur le métamodèle M2FLex. M2Flex a été utilisé pour définir une version flexibilisée de la méthodologie UsiXML qui est dédiée à la conception et au développement d'interfaces adaptables. Des ajustements à la version flexibilisée de UsiXML sont proposés afin de prendre en compte les résultats d'une expérience qui montre que 1) l'esthétique perçue améliore l'évaluation des utilisateurs seulement lors de la phase d'exposition à l'interface ; 2) l'utilisabilité augmente les évaluations des utilisateurs après utilisation de l'interface.

\section{Mots Clés}

Utilisabilité; esthétique; conception; processus; modèle.

\section{ABSTRACT}

Model driven engineering provides solutions to create user interfaces (UI), especially in the case of complex UIs such as adaptable UIs. However, they suffer from the poor quality of the generated UIs. This paper addresses this drawback by integrating aesthetics and usability study steps in a model driven development process, based in the M2Flex metamodel. M2Flex was used to define a "flexibilized" version of the UsiXML methodology, which is dedicated to the development of adaptable UIs. Adjustments to the "flexibilized" version of the UsiXML are submitted to be consistent with the findings of an experiment which shows that shows that 1) perceived aesthetics improves the user's evaluation only at the mere exposure stage; 2) usability improves the users' evaluation only after some use experience.
\end{abstract}

(C) ACM, 2016. This is the author's version of the work. It is posted here by permission of ACM for your personal use. Not for redistribution. The definitive version was published in Actes de la 28ème conférence francophone sur l'Interaction Homme-Machine, 2016.

http://dx.doi.org/10.1145/3004107.3004122

\section{Author Keywords \\ Usability; aesthetics; design; process; model}

\section{ACM Classification Keywords}

H.5.m. Information interfaces and presentation (e.g., HCI): Miscellaneous. H5.2. User Interface: Graphical User Interfaces

\section{INTRODUCTION}

Model Driven Engineering (MDE) provides powerful solutions to tackle the design and the implementation of User Interfaces (UIs), opening possibilities such as more evolving and reusable systems [13], greater quality, early detection of defects and inclusion of knowledge in executable models [30], and, carried to the extreme, dynamic adaptation to the context of use [2].

However, three main critiques are made to MDE. [34] identifies a high threshold of use - the complexity to master models and transformations-, the lack of wide walls - the limited possibilities of exploring various solutions - and a low ceiling, which stands the poor quality of generated UIs. We focus here on this last issue. Model-based UIs are indeed known for offering low aesthetics and not considering enough usability questions.

If UI development processes integrate usability studies, they do not offer many elements dealing with aesthetics issues. However, the importance of aesthetics is recognized on the users' perceived ease of use [20,42], on the overall impression $[42,35]$ and on the appraisal of a system [25].

In this paper, we propose to consider altogether usability and aesthetics in a model-driven development process. We hypothesize that usability and aesthetics have a reciprocal $[42,8,37,43,14]$ and timely influence $[1,15]$. So to identify when studying each aspect, we conduct a large-scale experiment on the impact of each one on the user's experience. In this experiment, aesthetics and usability are treated as independent variables so as to make it possible to establish the chronology of their influence on the user independently of their reciprocal influence. Our main finding suggests starting UI designs by aesthetics before introducing usability aspects: it sheds a new light on the way to consider UI design processes. Thus, we draw first implications upon this finding to improve user experience at different steps of a UI design process. 
The second section of the paper presents the state of the art about human-computer interaction design processes and aesthetics impact. The third and main section presents the development process, which will be extended with aesthetics and usability steps. Next we present and detail an experimental study to understand the impact of usability and aesthetics over time. Then we propose an extension of our process. Finally, the last section concludes and opens on perspectives.

\section{STATE OF THE ART}

User interface development processes are usually focused on usability aspect. They are based on iterative cycles, which allow designers to refine mock-ups or final UIs so as to obtain usable UIs [32,27]. These processes use techniques such as participatory design [31] or scenarios [16] to consider the user's point of view. For instance, with the worth based design approach, [6] introduces design principles that are more general than usability. However, the authors recommend starting the development process by identifying the value that the system has to offer and ending it with value measurement. Their approach remains principle-based without direct recommendation for UI design.

UI development processes don't offer many elements dealing with aesthetics issues, even if some of them offer large parts about usability. For instance, the Rational Unified Process RUP [19] only mentions that the software architect is "concerned with" aesthetics issue, whilst it insists several times on usability issues. The Diane+ method [41] makes it explicit that usability relies on ergonomics elements but also doesn't mention aesthetics. Model-based approaches, such as MACAO [7], Teallach [11] or UsiXML [44] offer detailed processes for creating the needed models and developing or generating the UIs, but do not focus on usability and aesthetics issues even if MACAO refers to generic software quality criteria from [17], which includes for instance the ease of use.

In the field of industrial design (which relates to the design of objects not excusively of the UIs), [46] focuses on improving aesthetics during design and states that it has a "relatively strong influence on the success of the product on the market". This paper presents an iterative approach for dealing with aesthetics issues. It recommends defining aesthetics criteria, assessing products against them and identifying new concepts from this evaluation. Authors exemplify their method with criteria such as "Harmony between subsystems", "Compactness", "Desired style", "Minimisation of the number of different forms". Even if this works relates to another domain and does not deal with usability issues, the recommendations show the relevance of aesthetics in a development process.

In guidance made of recommendations, several guides or approaches mentioned aesthetics. User-Centred Design [24,12] offers guidelines for designing UIs while including users in the process. They insist on increasing usability thanks to iterative, incremental development and user's evaluation, but they give no recommendation about aesthetics. Moreover, these works offer principles and techniques that are not included in a development process or more precisely, as [36] says, are "decoupled from the software development lifecycle". In a more practical way, some guides such as $[39,10]$ mention visual aesthetics because of its impact on usability. But their recommendations are not included in a process. Some UI design guides, such as [21], exclude the question of aesthetics, considering this is not very important.

From the related works, we can note that 1) even if users are consulted during processes, the focus is on usability and aesthetics is only lightly discussed (at best); 2) some recommendations exist about aesthetics but none of them is integrated into a UI development process.

So our contribution is to propose steps to consider altogether aesthetics and usability during a model-based process. The next section describes the process that we will extend.

\section{THE DEVELOPMENT PROCESS TO EXTEND}

In [3], M2Flex is a metamodel for creating flexible process models, i.e. processes that can be adapted to the project's situation (goals, constraints, team competencies and knowledge...). This metamodel is used in [4], to define a "flexibilized" version of the UsiXML methodology [44], which is dedicated to the design and development of adaptable UIs. As recommended in the Cameleon reference framework [2], the process (Fig. 1) is based on four kinds of models: Tasks, Domain, Abstract User Interface (AUI), Concrete User Interface" (CUI). Different strategies are proposed allowing designers not to create all models.

Figure 1 shows this flexibilized process model, with various strategies (1) connecting goals (2) and reified into more or less detailed activities (3), with the used (4) and produced (5) artefacts. Despite its huge ability to adapt to its users and their project, this process model remains perfectible, as it offers only guidance for creating models and transforming them into other models. There is no mention about ergonomics, even if it is awaited to be taken into account in an UI development. We thus want to complete this process by including recommendations for increasing the quality of the generated UIs, particularly on aesthetics and usability.

The way users estimate aesthetics and usability differently - that will in turn influence the stages considering these questions in the development process - has already been stated by [9], which shows that if people appreciate beauty, they don't want it to increase the cost of the product nor reduce its usability. Aesthetics must then be a bonus on the top of a usable UI. From the designers' point of view, it is also a key factor of success [42,38,5]. But for dealing with aesthetics and usability that might be opposite to each other without increasing drastically the cost, engineers 


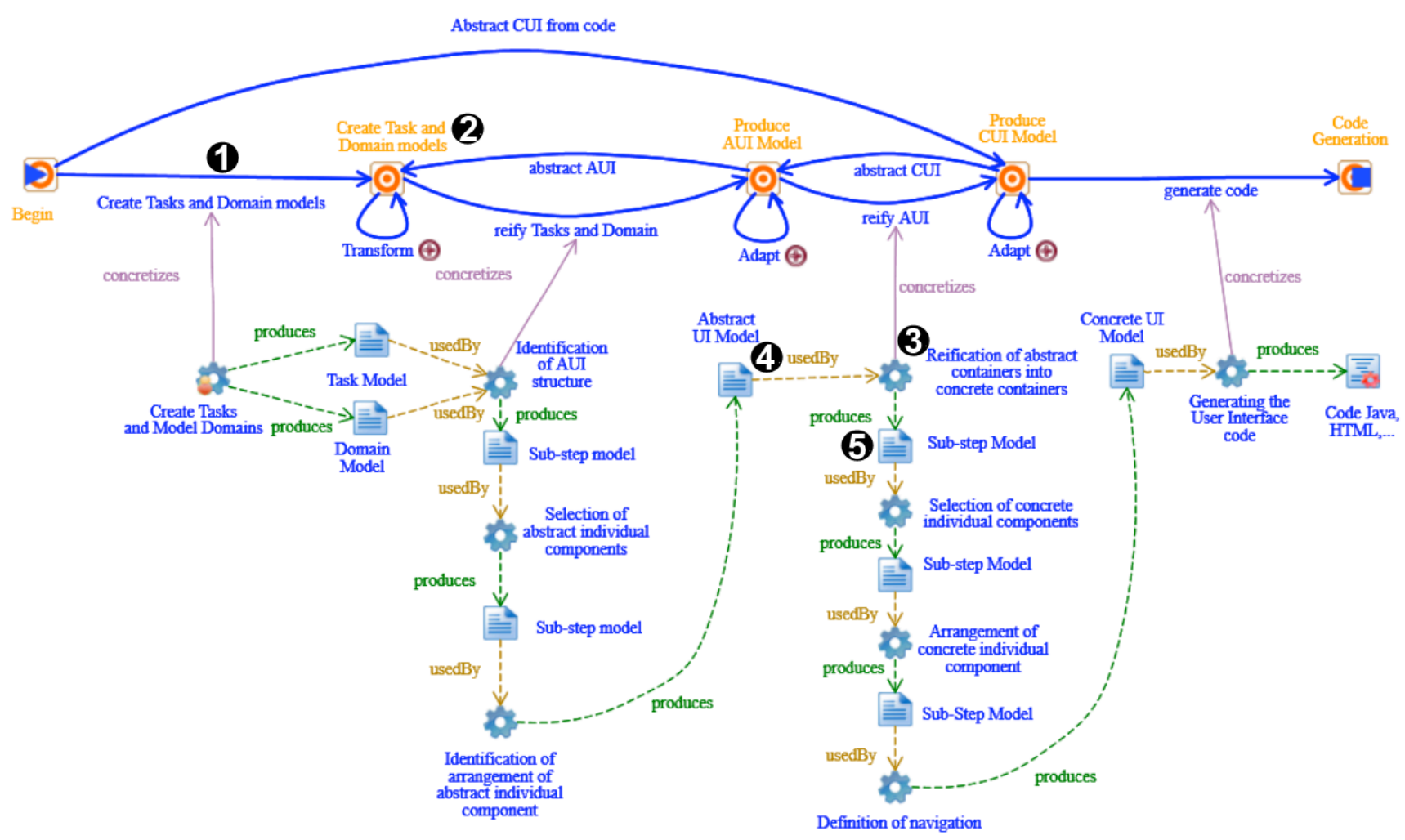

Figure 1 - UsiXML flexibilized process model according to the metamodel M2Flex

need to be guided. To be able to guide them, we first need to understand when aesthetics and usability impact users' experience to know when each of them has to be studied during the process. So we start by realizing an experience, which hypotheses that the two aspects are not taken into account at the same time by users. The experiment we drove for verifying this hypothesis is presented in the following section.

\section{EXPERIMENTAL STUDY}

\section{Goals and hypotheses}

The experiment examines how the users' experience (pleasantness, playfulness, and perceived value) differs depending on usability and aesthetics and how it evolves. Several studies about the use of interactive products show that these three dependant variables (pleasantness, playfulness, and perceived value) are the most relevant. These works show that the use of technological products induces affective responses (e.g., $[28,47])$. The fun aspect of using user interfaces and its impact on UI's worth have been highlighted by several studies in different fields of research. For instance, about technological acceptance models, [45] shows that playfulness positively impacts satisfaction while interacting. The positive aspect of such variable appears in several works such as modeling user experience on Internet (e.g., [33]) or using mobile phones [23]. Similarly, works done in the information system research field (e.g. [40]), underline the importance of pleasantness while interacting with a system. Finally, perceived value is also a key aspect of user experience while using user interfaces: a broad range of works from HCI, information system and marketing research fields states it (e.g., [26]).

In collaboration with marketing researchers, we conducted a large-scale experiment [18]. We examine the users' evaluation of their experience over time at two consecutive stages:

- Exposure (first stage): interface experience based on three tasks based on visual inspection of the web sites, without user interaction;

- Use (second stage): interface experience based on three tasks implying user interaction with the web sites.

We suggest that the role of interface aesthetics and usability should vary depending on the users' experience stage.

So the hypotheses are:

- H1: After the exposure stage, high (vs. low) interface aesthetics imply a higher (vs. lower) (a) pleasantness, (b) playfulness, and (c) perceived value of the interactive device.

- H2: After the exposure stage, the interface usability has no impact on (a) pleasantness, (b) playfulness, and (c) perceived value of the interactive device. 
- H3: After the use stage, high (vs. low) interface aesthetics has no impact on the different scores of (a) pleasantness, (b) playfulness, and (c) perceived value of the experience.

- H4: After the use stage, high (vs. low) interface usability implies a higher (vs. lower) (a) pleasantness, (b) playfulness, and (c) perceived value of the interactive device.

\section{Experimental Method}

The two-stages study asked participants to evaluate a travel website thanks to a questionnaire. The first stage (exposure) consisted in asking participants to evaluate it based on a visual inspection of the web sites, without user interaction. During the second stage (use), participants had to evaluate the same travel website after having manipulated it through user interaction. Versions of a same travel website were designed and developed according to two factors: high (vs. low) usability, and high (vs. low) aesthetics. So by combining these 2 values (low vs. high) for our two variables (aesthetics and usability), four versions of the website are created (Fig. 2).

\section{Procedure and Tasks}

In the first stage (exposure), in order to evaluate one assigned version of the four websites, the participants had to achieve three tasks, that just require to browse the website, related to three questions they had to answer to:
1. Which country does the travel agency promote?

2. What is the name of the first hotel that you can see on the travel agency's website?

3. What activity does the online travel agency offer?

We provided multiple choices answers for each question, with only one correct option.

In the second stage (use), the participants interacted with one website user interface and then answered questions. They were given three tasks to achieve. For instance, one of the tasks consists in searching for a 5stars hotel that offers a visit in the desert. While using the web-based user interface, they were asked to achieve four tasks related to the following questions:

1. How many 5-stars hotels offer a visit in the desert?

2. What is the name of the hotel that you found?

3. What city is this hotel located in?

4. What is the minimum price per person for this stay?

\section{Participants}

Using a panel from Qualtrics (an internet-based research company) and the online Qualtrics survey tool, we collected responses from 203 participants. The participants were randomly assigned to one specific version of the web site user interface (among the four

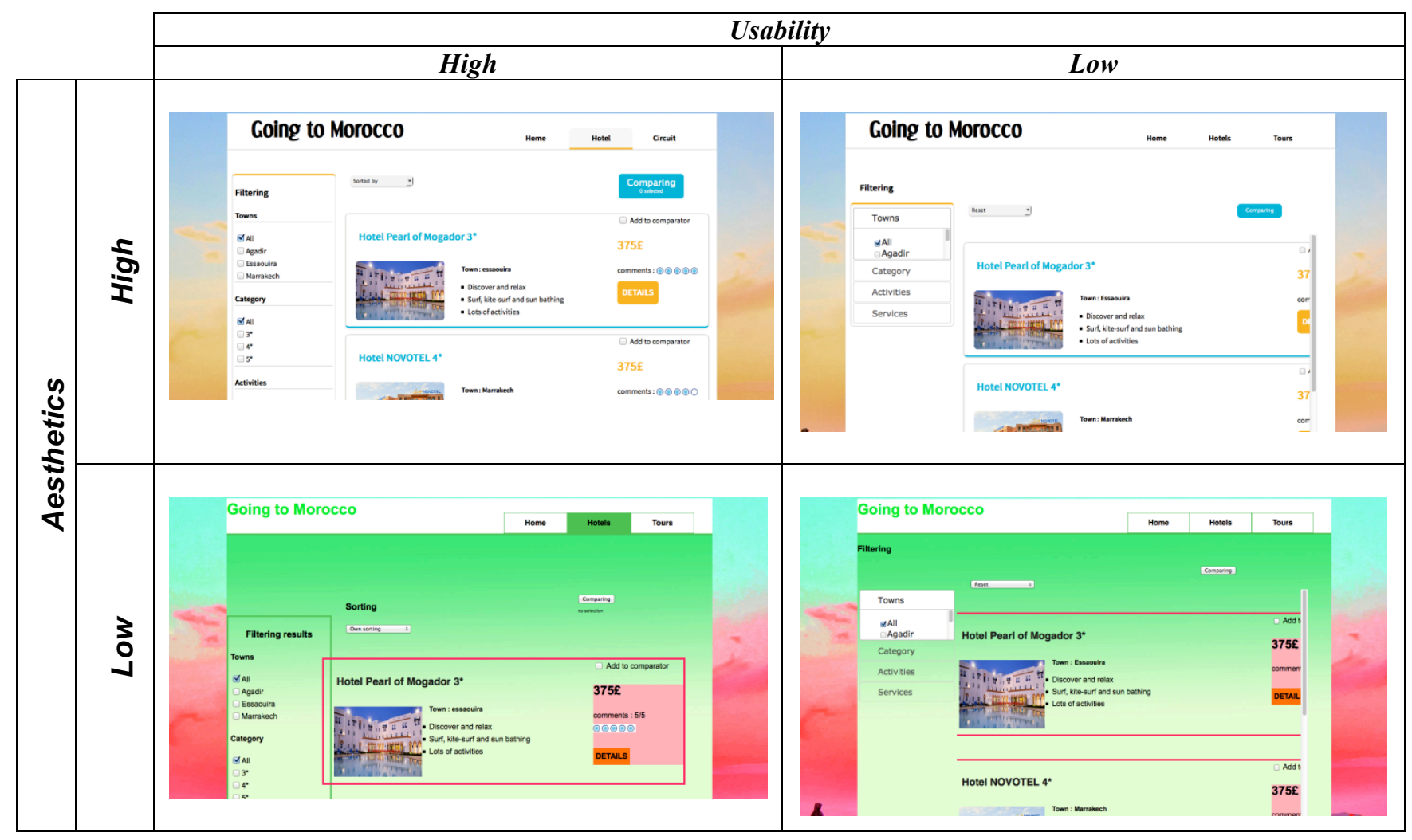

Figure 2: Four versions of a web site user interface: usability $\mathbf{x}$ aesthetics 


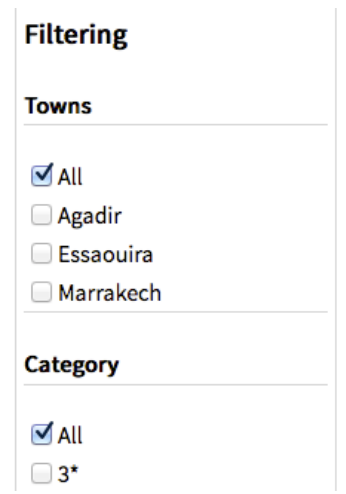

Filtering

Figure 3: Filtering criterion: expanded list (left: high usability) vs. cumbersome dynamic menu (right: low usability).

versions). The participants $(40.9 \%$ male, mean age $44.16, \sigma=13.95)$ were quite familiar with travel websites (mean=4.31, s.d. =1.65: in answer to the statement "I am familiar with travel websites"; from 1 "do not agree at all" to 7 "totally agree").

\section{UI designs and apparatus}

The study used mock travel agency's websites. The participants were asked to navigate one website to plan a hypothetical visit to Morocco, and they were then asked to evaluate the website. The participants were offered different options, such as various types of stay, hotels categories, cities, hotels comparison, activities, and types of package.

The four designs of the travel website were created by a website designer/developer (figure 2). To create these designs, basic functionalities and minimal user interaction were first specified through the generation of a task model and user interface mock-ups. As recommended by Tuch et al. [43], we manipulated-as independently as possible - the aesthetics and the usability of the website user interface. In order to verify the manipulations of aesthetics factors (high vs low) and usability factors (high vs low), a pretest has been driven with 58 students. Participants were exposed to the four UIs and evaluated their aesthetics and usability. Two scores for differences in average have been computed: one for low and one for high levels for aesthetics $\left(\mathrm{M}_{\text {diff aesth }}\right)$ and for usability $\left(\mathrm{M}_{\text {diff usab }}\right)$. Results show a statistically significant difference in the averages of high and low aesthetics $(\mathrm{t}(57)=15.40$, $\mathrm{p}<.0001, \mathrm{M}_{\text {diff aesth }}=2.30$, s.d.=1.13) as well as regarding usability $\quad\left(\mathrm{t}(57)=10.15, \quad \mathrm{p}<.0001, \quad \mathrm{M}_{\text {diff usab }}=1.35\right.$, s.d.=1.01). This validates the manipulation of aesthetics and usability factors in the four sites.

Thus, usability was first considered at the task level (i.e. interaction distance and workload) as well as in terms of concrete user interface. For the low usable version, the concrete user interface level was redesigned for increasing the workload, i.e. by using the navigational

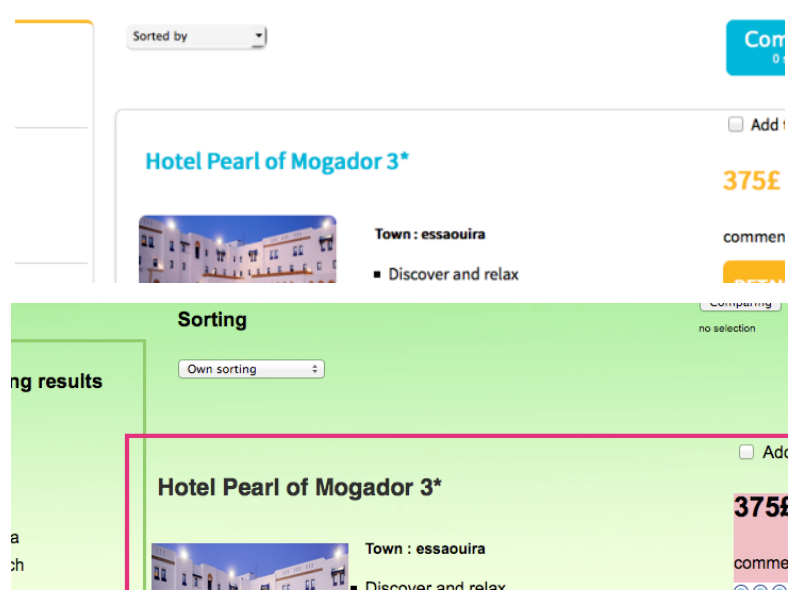

Figure 4: high (top) vs. low (bottom) interface-aesthetic.

factors related to the ease of information access (interaction distance, additional unnecessary articulatory subtasks). For instance, as shown in figure 3 , the list of hotels can be filtered using filtering criteria (left side of the user interface): the low usable version presents one criterion (vs. all criteria) at a time through a dynamic menu. Another example, some navigation elements were removed such as redundant hyperlinks.

To create a high vs. low interface-aesthetics, only the graphic factors were manipulated. As shown in figure 4, this included the background colour (bright vs. light), the framework shape (square vs. round), and the formatting (non-aligned vs. aligned) as studied in [29].

The four designs were included in the online survey thanks to Qualtrics' online application. It allows completing the survey while navigating the travel web site within a single web page.

\section{Study design: survey and measures}

The experiment used a three-factor mixed design. The between-subject independent variables were the interface usability with two levels (low and high), and the interface aesthetics with two levels (low and high). The within-subject independent variable was the user experience that includes two stages (exposure and use).

During the first stage (exposure), participants answered questions related to the tasks to achieve as well their exposure experience (pleasantness, playfulness, and perceived value).

During the second stage (use), after completing the three tasks, the participants answered questions similar to stage one about their use experience (pleasantness, playfulness, and perceived value). The participants answered additional questions relating to the manipulation (usability and aesthetics), and answered some profile questions (age, gender, and familiarity with travel websites). 
Thus, the four different versions are designed to operationalise the independent variables.

For measuring the participants' experience, the survey included several seven-point scale-based questions (e.g. $1=$ "strongly disagree" and 7="strongly agree"):

- Pleasantness: two items adapted from Venkatesh (2000): "this website is pleasant to use"; and "this website is nice to use".

- Playfulness: three items adapted from Venkatesh (2000): "this website is fun"; "this website is playful"; and "this website encourages a good mood".

- Perceived value: six items adapted from [38]: "overall, I think it is worth visiting this website"; "this website is useful"; "this website meets my expectations"; "visiting this website should be a good experience"; "this website is one that I can trust"; and "I believed the information provided by this website".

To ascertain the reliability of these measures, correlation calculations (Pearson and Cronbach's alpha) were achieved after each stage for each measure: it shows a very high correlation (over 0.927 at least with $\mathrm{p}$ $<0.001$ ) between items. As the scale properties were satisfactory, we created an average index for the three dependent variables (pleasantness, playfulness, and perceived value) at both the exposure and use stages to test our hypotheses.

Therefore, to test the exposure effect, we focused on the means of the indices relating to the website evaluations. To test the use effect, we compared the individual participants' website evaluations after the use stage with their evaluations at the exposure stage. We calculated a difference score for the use stage evaluations and for the exposure stage evaluations for the three dependent variables. This difference score estimates the improvement or the deterioration of the website evaluations (pleasantness, playfulness, and perceived value) due to the users' experience with the web site user interface.

To ascertain whether the high- (vs. low-) aesthetics/usability website led to higher (vs. lower) perceived aesthetics/usability, the participants assessed the perceived aesthetics and usability of the website. Therefore, to measure perceived usability and perceived aesthetics, we used respectively a four-item seven-point scale and a three-item seven-point scale, both adapted from [22]:

- Perceived usability: "this website allows information to be quickly found"; "this website does not need specific effort to find information"; "this website offers easy navigation"; and "this website offers a clear and understandable experience". Perceived aesthetics: "this website is visually attractive"; "this website is beautiful"; and "this website has an attractive design".

To ascertain the reliability of the measures, correlation calculations (Cronbach's alpha) were achieved after use stage for both measures: it shows a very high correlation (respectively 0.970 and 0.967 with p $<0.001$ ) between items.

As the reliability results were satisfactory, we computed two indices (average index) to test whether the perception of aesthetics and of usability respectively differ on the two factors: aesthetics (high vs. low) and usability (high vs. low).

\section{Results}

Perceived usability and aesthetics in line with the UI designs

The results confirm that UI usability impacts significantly and positively the perceived usability: ANOVA showed $\left(\mathrm{F}_{1,201}=7.22 \mathrm{p}=0.0078\right)$ that a website showing a high usability is perceived as easier to use than a website showing a low usability. Similarly, aesthetics impacts significantly and positively on the perceived aesthetics: ANOVA showed $\left(\mathrm{F}_{1,201}=7.22\right.$ $\mathrm{p}=0.0078$ ) that a website showing a high aesthetics is perceived as more appealing than a website showing a low aesthetics.

In the following, tables 1 and 2 show the results in tabular form and Figure 5 shows the results in graph form. 
Table 1: Results of two sample t-tests after exposure stage

\begin{tabular}{|c|c|c|c|c|c|}
\hline & & Mean & $\begin{array}{l}\text { Std. } \\
\text { dev. }\end{array}$ & $\begin{array}{c}\mathbf{t}_{201} \\
\text { (t-test) }\end{array}$ & $p$ value \\
\hline \multirow{4}{*}{ Pleasantness } & Low aesthetics & 4.18 & 1.41 & \multirow{2}{*}{2.00} & \multirow{2}{*}{0.046} \\
\hline & High aesthetics & 4.55 & 1.17 & & \\
\hline & Low usability & 4.46 & 1.23 & \multirow{2}{*}{0.944} & \multirow{2}{*}{0.346} \\
\hline & High usability & 4.49 & 1.37 & & \\
\hline \multirow{4}{*}{ Playfulness } & Low aesthetics & 4.52 & 1.33 & \multirow{2}{*}{3.482} & \multirow{2}{*}{$<0.001$} \\
\hline & High aesthetics & 5.09 & 0.97 & & \\
\hline & Low usability & 4.95 & 0.98 & \multirow{2}{*}{1.695} & \multirow{2}{*}{0.091} \\
\hline & High usability & 4.67 & 1.35 & & \\
\hline \multirow{4}{*}{ Perceived value } & Low aesthetics & 4.52 & 1.23 & \multirow{2}{*}{2.700} & \multirow{2}{*}{0.007} \\
\hline & High aesthetics & 4.93 & 0.93 & & \\
\hline & Low usability & 4.77 & 0.95 & \multirow{2}{*}{0.567} & \multirow{2}{*}{0.567} \\
\hline & High usability & 4.68 & 1.23 & & \\
\hline
\end{tabular}

Table 2: Results of two sample t-tests after use stage

\begin{tabular}{|c|c|c|c|c|c|}
\hline & & Mean & $\begin{array}{l}\text { Std. } \\
\text { dev. }\end{array}$ & $\begin{array}{c}\mathbf{t}_{201} \\
\text { (t-test) }\end{array}$ & $p$ value \\
\hline \multirow{4}{*}{ Pleasantness } & Low aesthetics & $-1.00 \%$ & $97.1 \%$ & \multirow{2}{*}{-0.784} & \multirow{2}{*}{0.433} \\
\hline & High aesthetics & $10.35 \%$ & $109.0 \%$ & & \\
\hline & Low usability & $-14.81 \%$ & $107.5 \%$ & \multirow{2}{*}{2.667} & \multirow{2}{*}{0.008} \\
\hline & High usability & $23.39 \%$ & $95.8 \%$ & & \\
\hline \multirow{4}{*}{ Playfulness } & Low aesthetics & $1,49 \%$ & $98.4 \%$ & \multirow{2}{*}{-0.963} & \multirow{2}{*}{0.336} \\
\hline & High aesthetics & $-13.59 \%$ & $123.5 \%$ & & \\
\hline & Low usability & $-33.84 \%$ & $125.2 \%$ & \multirow{2}{*}{3.506} & \multirow{2}{*}{$<0.001$} \\
\hline & High usability & $20.19 \%$ & $90.6 \%$ & & \\
\hline \multirow{4}{*}{ Perceived value } & Low aesthetics & $-3.55 \%$ & $88,5 \%$ & \multirow{2}{*}{-1.221} & \multirow{2}{*}{0.223} \\
\hline & High aesthetics & $-19.57 \%$ & $97.0 \%$ & & \\
\hline & Low usability & $-25.41 \%$ & $103.6 \%$ & \multirow{2}{*}{2.046} & \multirow{2}{*}{0.041} \\
\hline & High usability & $1.28 \%$ & $80.0 \%$ & & \\
\hline
\end{tabular}

\section{Exposure stage: aesthetics comes first}

The results emphasize that, after an exposure to the website display, a high aesthetic user interface provides a higher website evaluation than a low aesthetic user interface; however, user interface usability does not increase website evaluation at this stage.

Indeed, to test our hypotheses ( $\mathrm{H} 1$ and $\mathrm{H} 2)$, we computed two-sample t-tests (see Table 1, degrees of freedom=201) to test the impact of usability and aesthetics on the three dependent variables (pleasantness, playfulness, and perceived value).

As shown in Figure 5 (see Graph 1a), the pleasantness results show that aesthetics has a statistically significant positive impact on the perceived pleasantness of the website $(p=0.046)$. However, usability has no significant impact $(\mathrm{p}=0.346)$. 
As shown in Figure 5 (see Graph 1b), the playfulness results similarly show that aesthetics has a statistically significant positive impact on the perceived playfulness of the website $(p<0.001)$. However, usability has no significant impact $(\mathrm{p}=0.091)$.

As shown in Figure 5 (see Graph 1c), the perceived value results show that only aesthetics has a statistically significant positive impact on the perceived value of the website $(p=0.007)$. However, usability has no significant impact $(\mathrm{p}=0.567)$.

\section{Use stage: usability effect}

The results emphasize that, comparing the exposure stage to the use stage, a high user interface usability improves website evaluation, whereas a low interface usability reduces website evaluation. The results show that the user interface aesthetics does not modify the website evaluation relating to use.

Indeed, to test our hypothesis (H3 and H4), we computed two-sample t-tests (see Table 2, degrees of freedom=201) to test the impact of usability and aesthetics on the three different scores (pleasantness, playfulness, and perceived value).

As shown in figure 5 (see Graph $2 \mathrm{a}$ ), the pleasantness difference score (percentage) results show that aesthetics has no statistically significant impact on the website pleasantness difference score $(p=0.433)$. However, usability has a statistically significant and positive impact on the website pleasantness difference score $(\mathrm{p}=0.008)$.

As shown in figure 5 (see Graph $2 \mathrm{~b}$ ), the playfulness difference score (percentage) results similarly show that aesthetics has no statistically significant impact on the website playfulness difference score $(p=0.336)$. However, usability has a statistically significant and positive impact on the website playfulness difference score $(\mathrm{p}<0.001)$.

As shown in figure 5 (see Graph 2c), the perceived value difference score (percentage) result again shows that aesthetics has no statistically significant impact on the website perceived value difference score $(\mathrm{p}=0.223)$. Only usability has a statistically significant and positive impact on the website perceived value difference score $(p=0.041)$.

GRAPH 1 :Exposure effect: testing the influence of aesthetics and usability on website evaluation

(1a) Pleasantness

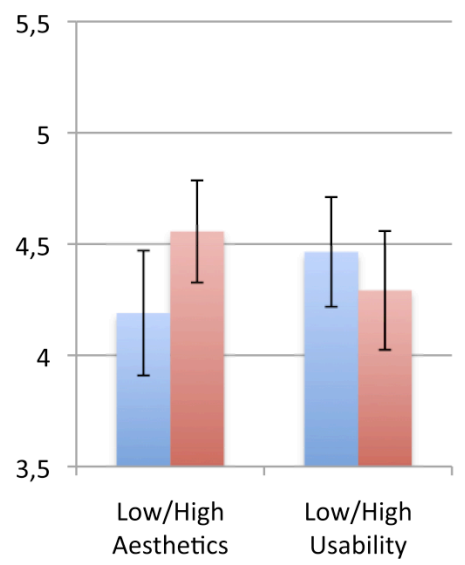

(1b) Playfulness

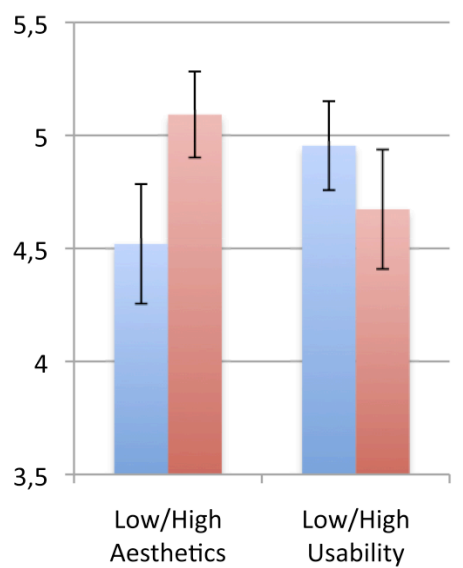

(1c) Perceived value

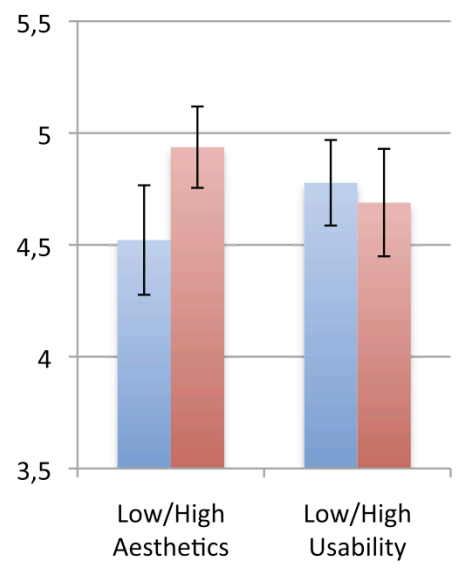

GRAPH 2 : Use effect: testing the influence of aesthetics and usability on website evaluation
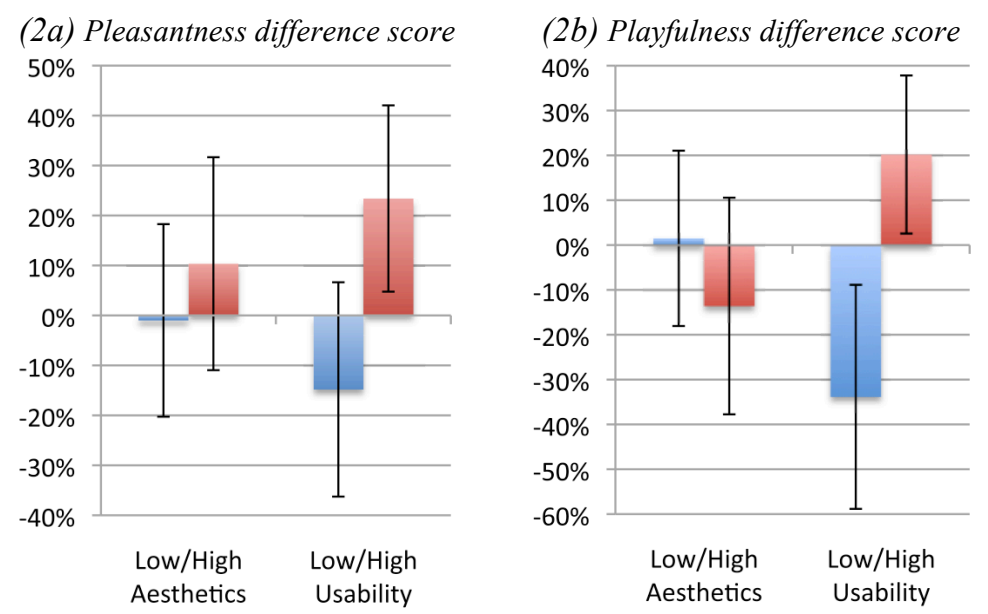

(2c) Perceived value difference score

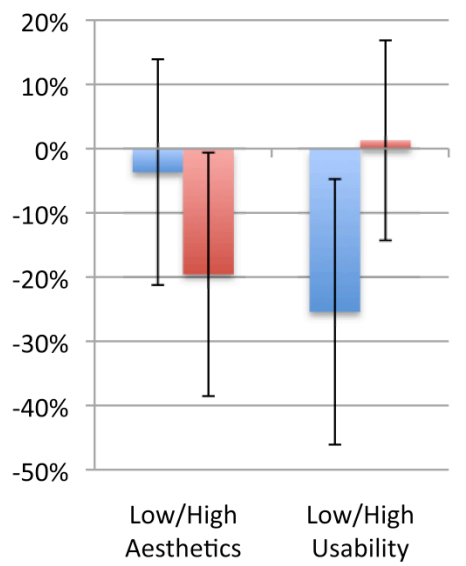

Figure 5: Exposure effect results (GRAPH1: 1a, 1b, 1c) and use effect results (GRAPH2: 2a, 2b, 2c) 


\section{Potential bias of the experiment}

At the exposure stage, we may observe that, for each measured values (pleasantness, playfulness, perceived value) the average is between 4 and 5 for seven-points scales. However, the range of values varies from 1 to 7 and the t-tests show significant differences for aesthetics. Looking at percentage difference score, significance is strengthening between exposure stage and use stage. For instance, for the low usable version, playfulness' average score decreases by $1.65(-33.84 \%)$ from 4.87 to 3.22 .

Although these results are encouraging, they must be mitigated as we designed this experiment considering very obvious differences between perceived aesthetics and perceived usability. For instance, we carefully designed the low aesthetics version in order to avoid impacting readability (guidance criteria) with inappropriate colours for labels. Furthermore, we underline that: (1) the visual inspection as well as the use of the web sites were achieved only once by the participants; (2) the tasks are non-critical and are without time and security constraints; (3) the experiment is limited to a single hand-crafted web-site. It advocates for additional experiments to strengthen these results. Currently, the experiment is extended with additional web sites.

\section{IMPACT OF THE EXPERIMENT ON THE DEVELOPMENT PROCESS}

Regarding UIs aesthetics, the results show that it only impacts the participants' evaluation at the exposure stage - when the users have to look for information through visual inspection of the web sites. In contrast, aesthetics do not influence the participants' evaluation at the use stage - when the users have to look for information based on their interaction with the website. Regarding user interface usability, the results show that usability does not influence the participants' evaluation when the users visually inspect the website (exposure stage). However, user interface usability improves the participants' evaluation when the users actually experience the website (use stage) through user interaction. In other words, user interface aesthetics only improves a user's evaluation of an interface after a mere exposure, whereas user interface usability only increases a user's evaluation after a use experience.
Thus, this experiment confirms that usability and aesthetics have a timely influence. Users are more impacted by aesthetics during the exposure stage, e.g. when they discover the application. This temporality can be taken into account by designers and developers. We therefore state a first recommendation that during a user interface design process, at early stage, designers should first study and propose the UIs aesthetics, and in a second phase focus on usability. Figure 6 shows the (end of the) resulting flexible process model after including the goals, strategies and activities corresponding to our experiment's results. Goals for exploring (1) aesthetics and evaluating it (2), as well as exploring usability (3) and evaluating it (4), have been added. The corresponding strategies have been included. As we need the process model to remain as flexible as possible, strategies $(5,6)$ have also been redefined for making it possible to deliver the software without having to consider aesthetics and usability. For similar reasons, we also added a strategy for considering aesthetics but not usability (7) or usability only (8). As UI development is an iterative process, strategy (9) makes it possible to refine the aesthetics and usability elaboration by returning to the Concrete UI production, earlier stages being accessible from there. Dotted lines $(5,6,7)$ signify that, although these strategies exist and make it possible to avoid aesthetics and usability considerations, we do not recommend enacting them.

As a complement to the impact on process models, we also draw a recommendation that is, while conducting usability evaluations and testing phases, aesthetics has to be tackled first as it might have a bias effect on the results.

\section{CONCLUSION AND PERSPECTIVES}

This paper presents a step towards integrating aesthetics and usability in a model based UI development process. An experiment shows the temporal influence of aesthetics and usability: it advocates for considering aesthetics before usability in a UI development process. So we extend a model based process to include aesthetics and usability study steps. To strengthen these results, the experiment is currently extended with additional web sites. This will allow us to refine the aesthetics step. Moreover, other aspects of user

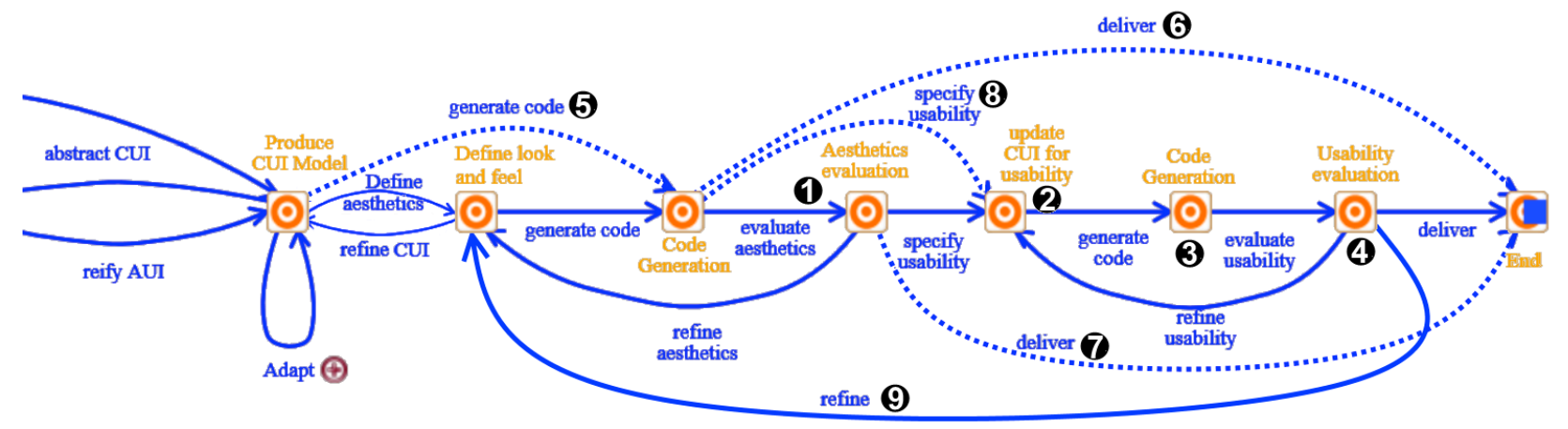

Figure 6 - UsiXML flexibilized process model including aesthetics and usability considerations 
experience can be studied, such as trust or perception of innovations. Their impact on the quality perceived by users must also be considered while designing a UI. Finally, we also will drive an experiment for evaluating if the proposed UI design process increases users' and designers' satisfaction.

\section{ACKNOWLEDGMENTS}

Realised in collaboration with the CERAG laboratory, this work has been funded by the UPMF University and the INNOVACS research federation. Thanks are also due to our marketing colleagues: Maud Damperat, Florence Jeannot, Eline Jongmans and Alain Jolibert.

\section{REFERENCES}

1. J. Bargas-Avila, and K. Hornbæk. 2011. Old wine in new bottles or novel challenges: a critical analysis of empirical studies of user experience. In Proceedings of the 2011 annual conference on Human factors in computing systems (CHI'2011), 2689-2698.

2. G. Calvary, J. Coutaz, and D. Thevenin. 2001. A Unifying Reference Framework for the Development of Plastic User Interfaces. Engineering for Human-Computer Interaction (EHCI 2001), 173-192.

3. E. Céret, S. Dupuy-Chessa, and G. Calvary. 2013. M2Flex: a process metamodel for flexibility at runtime. In proceedings of the Research Challenges in Information Science (RCIS'2013), 117-128.

4. E. Céret. 2014. Flexibilité des processus de développement à la conception et à l'exécution: application à la plasticité des Interfaces HommeMachine. PhD Dissertation, UGA. www.theses.fr/s93561

5. S. S. Chan, X. Fang, J. R. Brzezinski, Y. Zhou, S. $\mathrm{Xu}$ and J. Lam. 2002. Usability for Mobile Commerce Across Multiple Form Factors. Electronic Commerce Research. 3, 3, 187-199

6. G. Cockton. 2004. Value-centered HCI. In Proceedings of the third Nordic conference on Human-Computer Interaction (NODICHI'04), 149-1609.

7. J.-B. Crampes. 2002. Méthode Orientée-objet intégrale $M A C A O$ : démarche participative pour l'analyse, la conception et la réalisation de logiciels. Ellipse, Paris, France.

8. A. De Angeli, A. Sutcliffe, and J. Hartmann. 2006. Interaction, Usability and Aesthetics: What influences Users' Preferences. In Proceedings of the 6th conference on Designing Interactive systems (DIS'2006), 271-280.

9. S. Diefenbach, and M. Hassenzahl. 2009. The "Beauty Dilemma: beauty is valued but discounted in product choice". in Proceedings of the SIGCHI
Conference on Human Factors in Computing Systems (CHI '09), 1419-1426

10. O.W. Galitz. 2007. The essential guide to user interface design: an introduction to GUI design principles and techniques. Wiley.

11. T. Griffiths, et al. 2001. Teallach: a model-based user interface development environment for object databases. Interacting with Computers. 14, 1, 31 68 .

12. J. Gulliksen, B. Göransson, I. Boivie, J. Persson, S. Blomkvist, and Å. Cajander. 2005. Key Principles for User-Centred Systems Design. In HumanCentered Software Engineering - Integrating Usability in the Software Development Lifecycle, A. Seffah, J. Gulliksen, and M.C. Desmarais, eds. Springer Netherlands, 17-36.

13. B. Hamid, A. Radermacher, A. Lanusse, C. Jouvray, S. Gérard, and F. Terrier. 2008. Designing Fault-Tolerant Component Based Applications with a Model Driven Approach. Software Technologies for Embedded and Ubiquitous Systems. Springer, 9-20.

14. M. Hassenzahl, and A. Monk. 2010. The inference of perceived usability from beauty. HumanComputer Interaction. 25, 3, 235-260.

15. M. Hassenzahl 2004. The interplay of beauty, goodness, and usability in interactive products. Human-Computer Interaction. 19, 4, 319-349.

16. M. Hertzum. 2003. Making use of scenarios: a field study of conceptual design. International Journal of Human-Computer Studies. 58, 2, 215-239.

17. ISO/IEC 9126-1:2001(E): Software Engineering Product Quality - Part 1: Quality Model, ISO/IEC Std.

18. F. Jeannot, E. Jongmans, M. Dampérat, and A. Jolibert. 2016. A Crossed Influence of Usability and Aesthetics on Interactive Device Evaluation: Studying Exposure versus Use Effects. EMAC.

19. P. Kruchten. 2003. The Rational Unified Process: An Introduction (3rd ed.). Addison-Wesley.

20. M. Kurosu, and K. Kashimura. 1995. Apparent usability vs. inherent usability: experimental analysis on the determinants of the apparent usability. In Proceedings of the conference companion Human factors in computing systems (CHI'95), 292-293.

21. S. Lauesen. 2005. User interface design: a software engineering perspective. Pearson/Addison-Wesley.

22. S. Lee, S. Ha, and R. Widdows. 2011. Consumer responses to high-technology products: Product attributes, cognition, and emotions. Business Research. 64, 11, 1195-1200. 
23. W. Lee, and I. Benbasat. 2003. Designing an electronic commerce interface: attention and product memory as elicited by web design. Electronic Commerce Research and Applications. 2, 3, 240-253.

24. M. Maguire. 2001. Methods to support humancentred design. International Journal of HumanComputer Studies. 55, 587-634.

25. S. Mahlke, M. Thüring. 2007. Studying antecedents of emotional experiences in interactive contexts. In Proceedings of the SIGCHI conference on Human factors in computing systems (CHI'2007), 915918.

26. J. Marbach, C. Raquel Lages, and D. Nunan. 2016. Who are you and what do you value? Investigating the role of personality traits and customerperceived value in online customer engagement. Marketing Management, 32, 5-6, 502-525.

27. D. Mayhew. 1999. The usability engineering lifecycle. In Extended Abstracts on Human Factors in Computing Systems (CHI'99), 147-148.

28. D.G. Mick, and S. Fournier. 1998. Paradoxes of Technology: Consumer Cognizance, Emotions, and Coping Strategies. Consumer Research. 25, 2, 123143.

29. M. Minge. 2008. Dynamics of User Experience. In Positions paper in Workshop Research Goals and Strategies for Studying User Experience and Emotion (NORDICHI'2008).

30. P. Mohagheghi, M. Fernandez, J. Martell, M. Fritzsche, and W. Gilani. 2009. MDE Adoption in Industry: Challenges and Success Criteria. Models in Software Engineering, M.V. Chaudron, ed., 5459.

31. M. Muller. 2003. Participatory design: the third space in HCI. The human-computer interaction handbook, L. Erlbaum Associates Inc., 1051-1068.

32. J. Nielsen. 1993. Iterative User-Interface Design. Computer. 64, 32-41.

33. T.P. Novak, D.L. Hoffman, and Y-F Yung. 2000. Measuring the Customer Experience in Online Environments: A Structural Modeling Approach. Marketing Science, 19, 1, 22-42.

34. M. Resnick, B. Myers, K. Nakakoji, K. et al. 2005. Design Principles for Tools to Support Creative Thinking. In Proceedings of the NSF Workshop on Creativity Support Tools, 25-35.

35. B. Schenkman, and F. Jönsson. 2000. Aesthetics and preferences of web pages. Behaviour \& Information Technology. 19, 5, 367-377.

36. A. Seffah, and E. Metzker. 2004. Avoiding the usability pitfalls involved in managing the software development life cycle. Communications of the ACM. 47, 71-76.
37. A. Sonderegger, A. Uebelbacher, M. Pugliese, and J. Sauer. 2014. The Influence of Aesthetics in Usability Testing: the Case of Dual-Domain Products. In Proceedings of the SIGCHI Conference on Human Factors in Computing Systems (CHI'2014), 21-30.

38. J.E.M. Steenkamp, and I. Geyskens. 2006. How Country Characteristics Affect the Perceived Value of Web Sites. Marketing. 70, 3, 136-150.

39. D. Stone, C. Jarrett, M. Woodroffe, and S. Minocha. 2005. User Interface Design and Evaluation (1rst Edition), Morgan Kaufmann Publishers Inc.

40. J. Sutanto, E. Palme, C.-H. Tan, and C. Wei Phang. 2013. Addressing the Personalization-privacy Paradox: An Empirical Assessment from a Field Experiment on Smartphone Users. MIS Q. 37, 4: 1141-1164.

41. J.-C. Tarby, and M.-F. Barthet. 1996. The DIANE+ Method. In Computer-Aided Design of User Interfaces, 2nd International Workshop on Computer-Aided Design of User Interfaces (CADUI'96), 95-119.

42. N. Tractinsky, A. S. Katz, and D. Ikar. 2000. What is beautiful is usable. Interacting with Computers. $13,2,127-145$.

43. A. N. Tuch, S. P. Roth, K. Hornbæk, K. Opwis, and J. A. Bargas-Avila. 2012. Is beautiful really usable? Toward understanding the relation between usability, aesthetics, and affect in HCI. Computers in Human Behavior. 28, 5, 1596-1607.

44. UsiXML Consortium. 2011. UsiXML Method Specification.

45. V. Venkatesh. 2000. Determinants of Perceived Ease of Use: Integrating Control, Intrinsic Motivation, and Emotion into the Technology Acceptance Model. Info. Sys. Research, 11, 4, 342365.

46. R. Wagner, R. O. de Moraes, and R. S. M. de Castro. 2003. Method for Aesthetics Design Improvement. In Proceedings of the 14th International Conference On Engineering Design (ICED'03).

47. S. L. Wood, and C. Page Moreau. 2006. From Fear to Loathing? How Emotion Influences the Evaluation and Early Use of Innovations. Marketing. 70, 44-57. 